\title{
Capsular extension at ultrasound is associated with lateral lymph node metastasis in patients with papillary thyroid carcinoma: a retrospective study
}

Lei Ye ${ }^{1 *+}$, Lei Hu ${ }^{1+}$, Weiyong Liu ${ }^{1 *}$, Yuanyuan Luo ${ }^{3}$, Zhe Li ${ }^{1}$, Zuopeng Ding ${ }^{1}$, Chunmei Hu' ${ }^{1}$ Lin Wang ${ }^{1}$, Yajuan Zhu', Le Liu', Xiaopeng $\mathrm{Ma}^{2}$, Yuan Kong ${ }^{2}$ and Liangliang Huang ${ }^{4}$

\begin{abstract}
Background: In patients with papillary thyroid cancer (PTC), cervical lymph node metastasis (LNM) must be carefully assessed to determine the extent of lymph node dissection required and patient prognosis. Few studies attempted to determine whether the ultrasound (US) appearance of the primary thyroid tumor could be used to predict cervical lymph node involvement. This study aimed to identify the US features of the tumor that could predict cervical LNM in patients with PTC.
\end{abstract}

Methods: This was a retrospective study of patients with pathologically confirmed PTC. We evaluated the following US characteristics: lobe, isthmus, and tumor size; tumor position; parenchymal echogenicity; the number of lesions (i.e., tumor multifocality); parenchymal and lesional vascularity; tumor margins and shape; calcifications; capsular extension; tumor consistency; and the lymph nodes along the carotid vessels. The patients were grouped as no LNM (NLNM), central LNM (CLNM) alone, and lateral LNM (LLNM) with/without CLNM, according to the postoperative pathological examination.

Results: Totally, 247 patients, there were 67 men and 180 women. Tumor size of $>10 \mathrm{~mm}$ was significantly more common in the CLNM (70.2\%) and LLNM groups (89.6\%) than in the NLNM group (45.4\%). At US, capsular extension $>50 \%$ was most common in the LLNM group (35.4\%). The multivariable analysis revealed that age $(\mathrm{OR}=$ $0.203,95 \% \mathrm{Cl}: 0.095-0.431, P<0.001)$ and tumor size $(\mathrm{OR}=2.657,95 \% \mathrm{Cl}: 1.144-6.168, P=0.023)$ were independently associated with CLNM compared with NLNM. In addition, age ( $\mathrm{OR}=0.277,95 \% \mathrm{Cl}: 0.127-0.603, P=0.001)$, tumor size $(\mathrm{OR}=6.069,95 \% \mathrm{Cl}: 2.075-17.75, \mathrm{P}=0.001)$, and capsular extension $(\mathrm{OR}=2.09,95 \% \mathrm{Cl}: 1.326-3.294, \mathrm{P}=0.001)$ were independently associated with LLNM compared with NLNM.

Conclusion: Percentage of capsular extension at ultrasound is associated with LLNM. US-guided puncture cytology and eluent thyroglobulin examination could be performed as appropriate to minimize the missed diagnosis of LNM.

Keywords: Ultrasonography, Thyroid cancer, papillary, Metastasis, Lymph nodes

\footnotetext{
*Correspondence: 812449265@qq.com; Iwy_ultras@126.com

†Lei Ye and Lei Hu contributed equally to this work.

'Department of Ultrasound, Division of Life Science and Medicine, the First Affiliated Hospital of USTC, University of Science and Technology of China, No. 1, Tianehu Road, Hefei 230036, Anhui, China

Full list of author information is available at the end of the article
}

(c) The Author(s). 2021 Open Access This article is licensed under a Creative Commons Attribution 4.0 International License, which permits use, sharing, adaptation, distribution and reproduction in any medium or format, as long as you give appropriate credit to the original author(s) and the source, provide a link to the Creative Commons licence, and indicate if changes were made. The images or other third party material in this article are included in the article's Creative Commons licence, unless indicated otherwise in a credit line to the material. If material is not included in the article's Creative Commons licence and your intended use is not permitted by statutory regulation or exceeds the permitted use, you will need to obtain permission directly from the copyright holder. To view a copy of this licence, visit http://creativecommons.org/licenses/by/4.0/ The Creative Commons Public Domain Dedication waiver (http://creativecommons.org/publicdomain/zero/1.0/) applies to the data made available in this article, unless otherwise stated in a credit line to the data. 


\section{Background}

Papillary thyroid cancer (PTC) is a carcinoma that arises from the thyroid follicular cells, is classified as differentiated thyroid cancer, and accounts for about $80 \%$ of all thyroid cancers [1]. PTC may be sporadic or genetic and can be subtyped as well-differentiated or poorly differentiated, with each subtype encompassing multiple variants, some of which are more aggressive than others [1]. In the United States, the incidence of PTC increased from 4.56 per 100,000 person-years in 1974-1977 to 14.42 per 100,000 person-years in 2010-2013 [2]. The mortality rate of PTC is low, but positive lymph nodes are associated with lower survival $[3,4]$.

Although PTC is an indolent cancer [3, 4], it is frequently associated with cervical lymph node metastasis (LNM) [3, 5]. The incidence of central compartment LNM in patients with PTC can be as high as $80 \%$ [6]. In PTC, LNM occurs in a stepwise fashion. Cells from the primary tumor in the thyroid gland first spread to the central and ipsilateral lateral lymph node compartments via lymphatic drainage and then to the mediastinal and contralateral lateral lymph node compartments [7-9]. This sequential pattern of LNM implies that patients with lateral LNM (LLNM) will typically also have central LNM (CLNM). Nevertheless, discontinuous lymphatic spread occasionally occurs, leading to "skip metastasis," i.e., LLNM without CLNM [7-9]. Of course, the presence of LNM influences the prognosis and is associated with local tumor recurrence and poor patient survival [10]. Thus, in patients with PTC, cervical lymph node involvement must be carefully assessed to determine the extent of lymph node dissection required and patient prognosis.

Ultrasound (US) is the investigation of choice for both the pre- and postoperative surveillance in patients with PTC [11-13]. Grayscale US images can reveal highly specific features of the thyroid mass, such as microcalcifications and capsular extension, that are often impossible to detect using computed tomography (CT) or magnetic resonance imaging (MRI) [14-16]. In addition, compared with CT and MRI, US is inexpensive and fast, with no contraindications. Hence, it is beneficial to determine the significant ultrasound features that might indicate the presence of LNMs to help determine whether to perform central or lateral lymph node dissection.

Although the usefulness of the US to detect cervical LNM in PTC patients has been extensively investigated, few studies attempted to determine whether the US appearance of the primary thyroid tumor could be used to predict cervical lymph node involvement. Therefore, the present study aimed to identify the US features of the primary thyroid tumor used to predict cervical lymph node involvement in patients with PTC.

\section{Methods}

\section{Study design and population}

This retrospective study included patients with pathologically confirmed PTC who underwent preoperative thyroid US and surgical resection between April and September 2017 at the Anhui Province Hospital, The First Affiliated Hospital of the University of Science and Technology of China (Anhui Province, China). The study was approved by the Ethics Committee of the Anhui Province Hospital. Informed consent was waived due to the retrospective nature of this study.

The inclusion criteria were: 1) pathologically confirmed PTC; 2) underwent preoperative thyroid US; 3) underwent surgical resection; and 4) underwent lymph node dissection. The exclusion criteria were: 1) incomplete clinical data; or 2) US images were unclear or complete enough for analysis.

\section{Ultrasound}

All US examinations were performed using an iU22 device (Philips Medical Systems, Best, The Netherlands) equipped with an L12-5 linear transducer. The transducer was placed transversely over the midline of the body to evaluate the position of the thyroid gland relative to the midline. Each thyroid lobe was imaged in the longitudinal and transverse axes. We evaluated the following characteristics on the US: lobe, isthmus, and tumor size; tumor position; parenchymal echogenicity; the number of lesions (i.e., tumor multifocality); parenchymal and lesional vascularity; tumor margins and shape; calcifications; capsular extension; tumor consistency; and the lymph nodes along the carotid vessels. The presence or absence of chronic lymphocytic thyroiditis was also assessed in the US and confirmed on pathological examination. The tumor shape was based on the ratio of the anteroposterior diameter to the transverse diameter. Microcalcifications were defined as multiple bright punctate echoes, each measuring $<1 \mathrm{~mm}$, with or without acoustic shadows. The capsular extension was defined as the percentage of the perimeter of the thyroid nodule that was in contact with the thyroid capsule. Tumor echogenicity was described relative to the echogenicity of the surrounding muscle. The US examinations were performed by two physicians with more than 5 years of professional experience.

\section{Surgery}

The interval between ultrasound and surgery was $\leq 3$ days. All surgical procedures were performed by an experienced team of surgeons at the First Affiliated Hospital of the University of Science and Technology of China. As this is a retrospective study of consecutive patients, the patients were operated on by the surgeons operating thyroid cancer at our hospitals during the study 
period. The team included three associate chief physicians, nine attending physicians, and one resident physician (who was mainly an assistant). Unilateral thyroid lobectomy or isthmusectomy was performed in patients with unilateral cNO PTC, while bilateral thyroid lobectomy or isthmusectomy was performed in patients with bilateral cNO PTC. In addition, all patients underwent modified radical central and lateral lymph node dissection. Central lymph node dissection included the dissection of the pretracheal, prelaryngeal, and ipsilateral paratracheal lymph nodes. Lateral lymph node dissection involved the dissection of the lymph nodes in groups II to $\mathrm{V}$ while sparing the internal jugular vein, spinal accessory nerve, and sternocleidomastoid muscle. Lymph node metastases (macrometastases and micrometastases) and chronic lymphocytic thyroiditis were confirmed using the postoperative pathological examination. Lateral neck dissection was performed in the following cases: 1) US indicated suspicious lymph node metastasis; even though biopsy results were negative, dissection was performed considering the US results; 2) during the operation, it was found that the tumor was large and the lymph nodes in the central region were involved; or 3) the tumor was large and close to the superior lymph nodes, and lymph node metastasis in regions II and III are frequent, and dissection was performed for prevention. Pathological results were determined by two pathologists with more than 5 years of experience. The pathologists were blind to the US data.

\section{Grouping}

The patients were divided into three groups based on their lymph node status: (i) no LNM, NLNM group; (ii) CLNM alone without LLNM, CLNM group; and (iii) LLNM with or without CLNM, LLNM group. CLNM was defined as metastasis to the group VI lymph nodes (i.e., the central lymph nodes). LLNM was defined as the involvement of the lymph nodes in groups II to $\mathrm{V}$ (i.e., the lateral lymph nodes) [17].

\section{Observational indexes}

The demographic information like age and gender and all clinical, imaging, and pathological features were collected from the clinical records. The following factors were evaluated as potential predictors of LNM in patients with PTC: maximum tumor dimension $(\leq 10 \mathrm{~mm}$ vs. $>10 \mathrm{~mm})$ [18], age (<45 years vs. $\geq 45$ years) [19], tumor position (upper, middle, or lower third of the thyroid, or the thyroid isthmus), tumor multifocality (single lesion vs. multiple lesions), tumor margins (regular vs. irregular), tumor shape (round-to-ovoid vs. taller-thanwide), calcification (absent, microcalcification, or other types), capsular extension $(0,<25,25-50 \%$, and $>50 \%$; Fig. 1), echogenicity (isoechoic, hypoechoic, or markedly hypoechoic), tumor consistency (solid vs. mixed solidcystic), and chronic lymphocytic thyroiditis (absent vs. present). A taller-than-wide shape was identified when the ratio of the anteroposterior diameter to the transverse diameter was $\geq 1$. Data were double entered to ensure exactness and minimize bias.

\section{Statistical analysis}

Statistical analyses were performed using SAS 9.1 for Windows (SAS Institute, Cary, NY, USA). Continuous variables were presented as means \pm standard deviations (SD) or as medians and interquartile ranges (IQR), according to their distribution, as determined by the Kolmogorov-Smirnov test. The continuous variables were compared by ANOVA, with the least significant difference (LSD) test and the Bonferroni method for pairwise comparison. Categorical variables were reported as frequencies and percentages and were compared using the chi-square or Fisher's exact test. The incidence of individual US features was analyzed using the Cochran-Mantel-Haenszel chi-square test. Logistic regression analysis was performed to estimate the association of certain parameters with LNM, and the results were presented as odds ratios (OR) with a 95\% confidence interval (CI). Differences were considered statistically significant at $P<0.05$.

\section{Results}

\section{General characteristics}

A total of 372 patients underwent preoperative thyroid US for the assessment of a thyroid nodule. Postoperative pathological examination confirmed PTC in 247 of these patients, who were included in the study. Among the 247 patients, there were 67 men and 180 women. The mean age was $44.2 \pm 11.6$ years (range, $12-76$ years). The patients were grouped as NLNM group, 152 patients; CLNM group, 47 patients; and LLNM, 48 patients (LLNM+CLNM, 31 patients; LLNM alone, 17 patients). The general characteristics of the patients are shown in Table 1. Sex distribution did not differ among the NLNM (37 men, 115 women), CLNM (14 men, 33 women), and LLNM groups (16 men, 32 women; $P=$ 0.427). The patients in the CLNM (mean age, $39.7 \pm$ 10.9 years) and LLNM groups $(40.1 \pm 10.8$ years $)$ were significantly younger than those in the NLNM group $(46.9 \pm 11.3$ years $)(P<0.001)$.

\section{Factors associated with LNM}

The frequencies of tumor location, multifocality, and chronic lymphocytic thyroiditis did not differ among the three groups (all $P>0.05$ ). Tumor size of $>10 \mathrm{~mm}$ was significantly more common in the CLNM (70.2\%) and LLNM groups (89.6\%) than in the NLNM group (45.4\%) $(\mathrm{P}<0.001)$. Most tumors had irregular margins, 
a

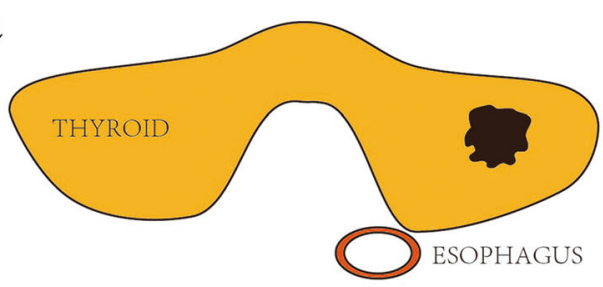

b

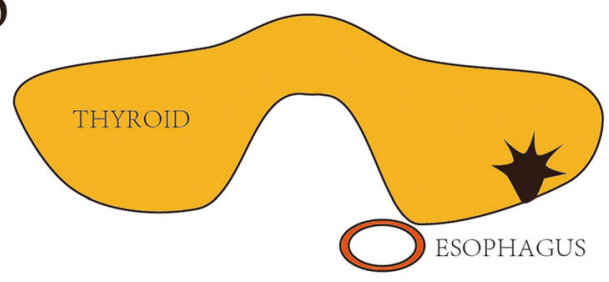

$\mathrm{c}$

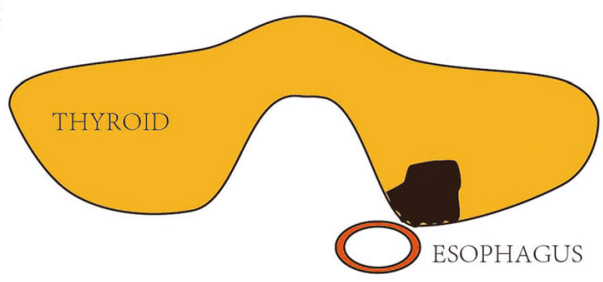

d

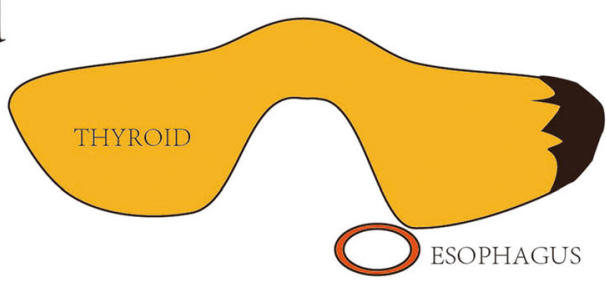

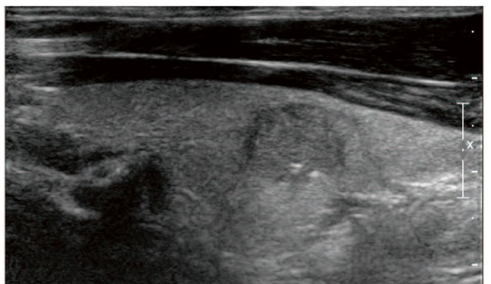
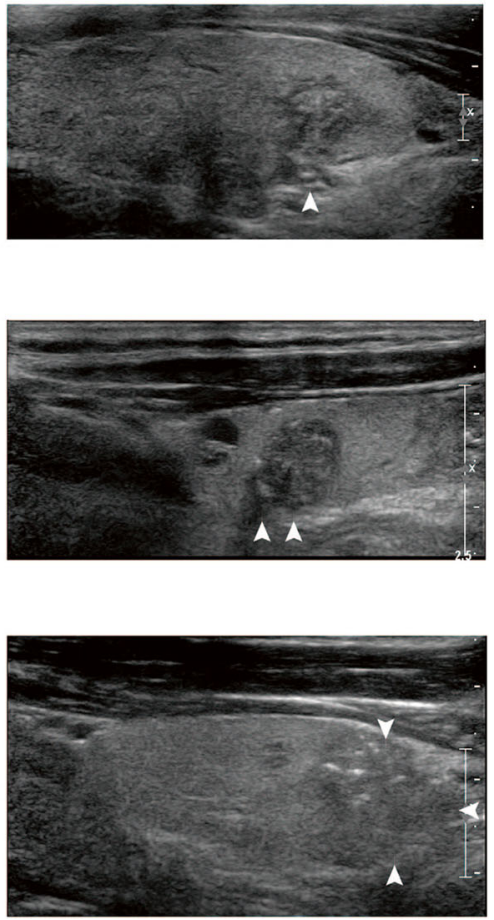

Fig. 1 Classification of capsular extension in papillary thyroid cancer: no contact (a), < 25\% contact (b), 25-50\% contact (c), and > 50\% contact (d)

microcalcifications, hypoechoic appearance, and solid consistency, and the frequency of these four characteristics did not differ among the three groups $(P=0.825$, $P=0.240, \quad P=0.943$, and $P=0.640$, respectively). A round-to-ovoid shape was significantly more common in the LLNM group (81.3\%) than in the NLNM (61.2\%) and CLNM groups $(76.6 \%)(P=0.013)$. Capsular extension $>50 \%$ was most common in the LLNM group (35.4\%) $(P<0.001)$ (Table 2).

\section{Multivariable logistic regression analysis}

A multivariable logistic regression analysis of the factors that significantly differed between the three groups was performed (Table 3). The analysis revealed that age $(\mathrm{OR}=0.203,95 \% \mathrm{CI}$ : $0.095-0.431, \mathrm{P}<0.001)$ and tumor size $(\mathrm{OR}=2.657,95 \% \mathrm{CI}: 1.144-6.168, P=0.023)$ were independently associated with CLNM compared with NLNM. In addition, age $(\mathrm{OR}=0.277,95 \% \mathrm{CI}: 0.127-$ $0.603, P=0.001)$, tumor size $(\mathrm{OR}=6.069,95 \% \mathrm{CI}$ : $2.075-$
17.75, $\mathrm{P}=0.001$ ), and percentage of capsular extension $(\mathrm{OR}=2.09,95 \% \mathrm{CI}: 1.326-3.294, \mathrm{P}=0.001)$ were independently associated with LLNM compared with NLNM.

\section{Discussion}

Given that few studies attempted to determine whether the ultrasound appearance of the primary thyroid tumor could be used to predict cervical LNM, this study aimed to identify the ultrasound features of the primary thyroid tumor that could be associated with cervical LNM in PTC. The results suggest that age and tumor size were independently associated with CLNM in patients with PTC. Age, tumor size, and percentage of capsular extension at ultrasound were independently associated with LLNM.

This study revealed that among patients with suspected PTC, age $<45$ years, tumor size $>10 \mathrm{~mm}$, and capsular extension $>50 \%$ were independently associated 
Table 1 Clinicopathological characteristics of the patients with papillary thyroid carcinoma $(n=247)$

\begin{tabular}{|c|c|c|c|c|}
\hline Characteristics & NLNM $(n=152)$ & CLNM $(n=47)$ & LLNM $(n=48)$ & $P$ \\
\hline Age (years), mean $\pm S D$ & $46.9 \pm 11.3$ & $39.7 \pm 10.9$ & $40.1 \pm 10.8$ & $<0.001$ \\
\hline$<45$ & $56(36.8)$ & $34(72.3)$ & $31(64.6)$ & $<0.001$ \\
\hline$\geq 45$ & $96(63.2)$ & $13(27.7)$ & $17(35.4)$ & \\
\hline Sex (male), n (\%) & $37(24.3)$ & $14(29.8)$ & $16(23.3)$ & 0.427 \\
\hline Hashimoto's thyroiditis, n (\%) & $35(23.0)$ & $15(31.9)$ & $13(29.2)$ & 0.446 \\
\hline Tumor size (mm), median (IQR) & $9.4(7,14)$ & $15(10,21)$ & $18(14,23.75)$ & $<0.001$ \\
\hline$\leq 10$ & $83(54.6)$ & $14(29.8)$ & $5(10.4)$ & $<0.001$ \\
\hline$>10$ & $69(45.4)$ & $33(70.2)$ & $43(89.6)$ & \\
\hline \multicolumn{5}{|c|}{ Tumor location, n (\%) } \\
\hline Upper third & $29(19.1)$ & $8(17.0)$ & $9(18.7)$ & $0.945^{f}$ \\
\hline Middle third & $86(56.6)$ & $24(51.1)$ & $26(54.2)$ & \\
\hline Lower third & $35(23.0)$ & $14(29.8)$ & $12(25.0)$ & \\
\hline Isthmus & $2(1.3)$ & $1(2.1)$ & $1(2.1)$ & \\
\hline \multicolumn{5}{|c|}{ Pathological multifocality, n (\%) } \\
\hline Single & $129(84.9)$ & $35(74.5)$ & $37(77.1)$ & 0.643 \\
\hline Multiple & $23(15.1)$ & $12(25.5)$ & $11(22.9)$ & \\
\hline \multicolumn{5}{|c|}{ Pathological type, n (\%) } \\
\hline Papillary microcarcinoma & $64(42.1)$ & $18(38.3)$ & $24(50.0)$ & $0.345^{f}$ \\
\hline Papillary carcinoma & $86(56.6)$ & $28(59.6)$ & $24(50.0)$ & \\
\hline Medullary carcinoma & 0 & $1(2.1)$ & 0 & \\
\hline Follicular adenocarcinoma & $2(1.3)$ & 0 & 0 & \\
\hline
\end{tabular}

${ }^{\mathrm{f}}$ Fisher's exact test

NLNM no lymph node metastasis, CLNM central lymph node metastasis, LLNM lateral lymph node metastasis, SD standard deviation; IQR: interquartile range

with LNM. The overall incidence of cervical LNM in the present study was approximately $38.5 \%$ (95/247), consistent with previous reports [6]. The incidence of skip metastasis (i.e., LLNM without CLNM) was 6.9\% (17/ 247). Women accounted for more than $70 \%$ of the patients in each group, and the sex distribution was similar among the three groups. Although PTC incidence is higher among women, men require specialized thyroid checkups to enable the early detection of thyroid tumors [20]. Younger age ( $<45$ years) has been associated with an increased risk of CLNM [20]. In a previous study, the univariable analysis showed that LNM is more likely among men, patients younger than 45 years, patients with multifocal tumors, and patients with local infiltration [21]. Consistent with this, the present study showed that patients were more likely to be younger than 45 years old in the CLNM (72.3\%) and LLNM groups (64.6\%) than in the NLNM group (36.8\%).

Tumor shape and capsular extension at ultrasound were related to cervical LNM, but tumor margins, calcification, echogenicity, and consistency were not. Previous studies reported that a taller-than-wide shape is a useful predictor of thyroid malignancy [22-24]. The dense fibrosis in a PTC may lead to decreased compressibility and a taller-than-wide shape [23]. In the present study, a taller-than-wide shape was significantly more common in the NLNM group (38.8\%) than in the CLNM (23.4\%) or LLNM group (18.7\%).

Capsular extension, specifically the degree of capsular extension and capsular disruption, can predict extrathyroidal extension and invasive thyroid cancer [25]. Skip metastases are more common in patients with PTC and primary tumor capsular invasion than patients without capsular invasion [26]. In the present study, capsular extension $>50 \%$ was the most common in the LLNM group (35.4\%). Irregular tumor margins are a sign of malignancy. In this study, the incidence of non-smooth margins was more than $90 \%$ in all three groups. This high incidence might be attributable to the use of the high-resolution US and strict observation standards. Microcalcification was frequently observed in the present study, but its incidence did not significantly differ among the three groups. Only a few studies included capsular extension as one of the US features $[5,14,26$, 27]. The present study suggests that capsular invasion is significantly associated with LLNM. In other words, when a capsular extension is found by US, the patient should be considered at a relatively high risk of LLNM, and the surgeons might consider performing lateral lymph node dissection. 
Table 2 Patients and ultrasound findings of papillary thyroid carcinoma $(n=247)$

\begin{tabular}{|c|c|c|c|c|}
\hline Characteristics, n (\%) & NLNM $(n=152)$ & CLNM $(n=47)$ & LLNM $(n=48)$ & $P$ \\
\hline \multicolumn{5}{|c|}{ Shape } \\
\hline Regular & 45 (29.6) & $9(19.2)$ & $12(25.0)$ & 0.351 \\
\hline Irregular & $107(70.4)$ & $38(80.9)$ & $36(75.0)$ & \\
\hline \multicolumn{5}{|c|}{ Margin } \\
\hline Smooth & $9(5.8)$ & $1(2.1)$ & $3(6.3)$ & $0.825^{f}$ \\
\hline Non-smooth & $143(94.2)$ & $46(97.9)$ & $45(93.8)$ & \\
\hline \multicolumn{5}{|c|}{ Aspect ratio } \\
\hline$<1$ & $93(61.2)$ & $36(76.6)$ & $39(81.3)$ & 0.013 \\
\hline$>1$ & $59(38.8)$ & $11(23.4)$ & $9(18.7)$ & \\
\hline \multicolumn{5}{|c|}{ Calcification } \\
\hline Absent & $35(22.9)$ & $8(17.0)$ & $6(12.5)$ & $0.240^{f}$ \\
\hline Macrocalcification & $102(68.0)$ & $37(78.7)$ & $35(72.9)$ & \\
\hline Microcalcification & $14(9.1)$ & $2(4.3)$ & $7(14.6)$ & \\
\hline \multicolumn{5}{|c|}{ Extension toward the capsule } \\
\hline 0 & $42(27.6)$ & $9(19.2)$ & $3(6.3)$ & $<0.001^{f}$ \\
\hline$<25 \%$ & $43(28.3)$ & $13(27.7)$ & $7(14.6)$ & \\
\hline $25-50 \%$ & $55(36.2)$ & $16(34.0)$ & $21(43.8)$ & \\
\hline$>50 \%$ & $12(7.9)$ & $9(19.1)$ & $17(35.4)$ & \\
\hline \multicolumn{5}{|l|}{ Echo } \\
\hline Isoechoic & $2(1.3)$ & $0(0)$ & $0(0)$ & $0.943^{f}$ \\
\hline Hypoechoic & $142(93.4)$ & $45(95.7)$ & $42(87.5)$ & \\
\hline Markedly hypoechoic & $8(5.3)$ & $2(4.3)$ & $6(12.5)$ & \\
\hline \multicolumn{5}{|c|}{ Internal structure } \\
\hline Solid & $150(98.7)$ & $46(97.9)$ & $48(100.0)$ & $0.640^{f}$ \\
\hline Mixed solid-cystic & $2(1.3)$ & $1(2.1)$ & $0(0)$ & \\
\hline
\end{tabular}

${ }^{\mathrm{f}}$ Fisher's exact test

NLNM no lymph node metastasis, CLNM central lymph node metastasis, LLNM lateral lymph node metastasis

Tumor size is associated with the extent of cancer cell proliferation, and a faster rate of cell proliferation correlates with a higher risk of CLNM [28]. Accordingly, tumor size is a strong predictor of microscopic CLNM and LLNM in NO PTC patients [29]. In the present study, tumor size was largest in the LLNM group $(P<$ 0.001 ). A tumor size $>10 \mathrm{~mm}$ was more frequent in the CLNM (70.2\%) and LLNM groups (89.6\%) than in the NLNM group (45.4\%).

A recent study revealed that Delphian lymph node (DLN) metastasis in PTC patients was related to tumor location in the isthmus or upper third of the thyroid [28]. Azizi et al. [30] found that thyroid nodules in the isthmus were more likely to be malignant than nodules elsewhere in the gland. In the present study, 55.1\% (136/ 247) of the patients had tumors in the middle third of the thyroid. Only four patients had tumors located in the isthmus. Tumor location did not significantly differ among the three groups.
Most patients with PTC (18-87\%) have multifocal tumors. Some studies found that multifocality is associated with a high risk of LNM among patients with thyroid microcarcinomas, but other studies reported that the risk of LNM does not differ between those with unifocal and multifocal PTC $[21,31]$. In the present study, the incidence of multifocality did not differ among the three groups.

Hashimoto's thyroiditis is the most common form of autoimmune thyroid disease, with an incidence rate of about $2 \%$ in the general population. Some investigators reported that Hashimoto's thyroiditis is a risk factor for PTC, while others found no correlation between the two [32]. A study revealed that the incidence of Hashimoto's thyroiditis among PTC patients ranges from 9 to 58\% [27]. In the present study, the incidence of Hashimoto's thyroiditis did not significantly differ among the three groups. 
Table 3 Multivariable logistic regression analysis for the presence of CLNM or LLNM compared with NLNM $(n=247)$

\begin{tabular}{llll}
\hline Characteristics & OR & $\mathbf{9 5 \% C l}$ & $\boldsymbol{P}$ \\
\hline CLNM & & & \\
Age (year) & 0.203 & $0.095-0.431$ & $<0.001$ \\
Tumor size (mm) & 2.657 & $1.144-6.168$ & 0.023 \\
Extension toward the capsule & 1.197 & $0.809-1.772$ & 0.368 \\
Aspect ratio > 1 & 0.878 & $0.374-2.064$ & 0.766 \\
LLNM & & & \\
Age (year) & 0.277 & $0.127-0.603$ & 0.001 \\
Tumor size (mm) & 6.069 & $2.075-17.75$ & 0.001 \\
Extension toward the capsule & 2.09 & $1.326-3.294$ & 0.001 \\
Aspect ratio > 1 & 1.006 & $0.394-2.573$ & 0.989 \\
\hline
\end{tabular}

OR odds ratio, Cl confidence interval, NLNM no lymph node metastasis, CLNM central lymph node metastasis, LLNM lateral lymph node metastasis

Partially cystic and iso- or hyperechoic nodules are generally benign, with a low malignancy risk. In the present study, most of the tumors were hypoechoic, and the incidence of hypoechogenicity did not differ among the three groups. PTC is almost always solid, and cystic changes in PTC are rare. Some studies showed that mixed echogenicity (cystic component $>50 \%$ ), accompanied by a honeycomb appearance, is an indication of benignity [22].

There are several potential limitations to this study. First, this is a retrospective study, and further prospective study is necessary to confirm the results. Second, we did not compare the US features of lymph nodes with and without metastasis. Third, we did not examine the association between capsular extension at ultrasound and the actual capsular contact at the histological level. Fourth, the signal intensity-related parameters showed inter-individual differences and were affected by certain conditions. Fifth, the subtypes of PTC were not recorded. Sixth, the BRAF V600E mutation was not examined. Finally, only patients with PTC were included in this study and not patients with medullary or undifferentiated carcinomas. This study, therefore, does not represent all the pathological subtypes of thyroid carcinoma.

\section{Conclusion}

Age and the size of the thyroid cancer lesion might be related to CLNM and LLNM. In addition, a capsular extension of nodules and thyroid, which is examined in only a few studies, is associated with LLNM. When suspicious lymph nodes are found preoperatively, USguided puncture cytology and eluent thyroglobulin examination could be performed to minimize the missed diagnosis of LNM.

\section{Abbreviations}

PTC: Papillary thyroid cancer; NLNM: no lymph node metastasis;

CLNM: central LNM; LLNM: lateral LNM; US: Ultrasound; CT: computed tomography; MRI: magnetic resonance imaging; DLN: Delphian lymph node

Acknowledgments

None.

\section{Authors'contributions}

$\mathrm{L}$ Ye carried out the studies, participated in collecting data, and drafted the manuscript; L Hu carried out the studies, participated in collecting data, and drafted the manuscript; WY Liu performed the statistical analysis and participated in its design; YY Luo carried out the studies, participated in collecting data, and drafted the manuscript; Z Li participated in acquisition, analysis, or interpretation of data; ZP Ding participated in acquisition, analysis, or interpretation of data; CM Hu participated in acquisition, analysis, or interpretation of data; $L$ Wang participated in acquisition, analysis, or interpretation of data; YJ Zhu participated in acquisition, analysis, or interpretation of data; L Liu participated in acquisition, analysis, or interpretation of data; XP Ma performed the statistical analysis and participated in its design, participated in acquisition, analysis, or interpretation of data, and draft the manuscript; $Y$ Kong performed the statistical analysis and participated in its design, participated in acquisition, analysis, or interpretation of data, and draft the manuscript; LL Huang performed the statistical analysis and participated in its design, participated in acquisition, analysis, or interpretation of data, and draft the manuscript; All authors read and approved the final manuscript.

\section{Funding}

None

\section{Availability of data and materials}

The datasets used and/or analyzed during the current study are available from the corresponding author on reasonable request.

\section{Declarations}

Ethics approval and consent to participate

The study was approved by the Ethics Committee of the Anhui Province Hospital. Informed consent was waived due to the retrospective nature of this study.

\section{Consent for publication}

Not applicable.

\section{Competing interests}

The authors declare that they have no competing interests.

\section{Author details}

${ }^{1}$ Department of Ultrasound, Division of Life Science and Medicine, the First Affiliated Hospital of USTC, University of Science and Technology of China, No. 1, Tianehu Road, Hefei 230036, Anhui, China. ²Department of Surgery, Division of Life Science and Medicine, the First Affiliated Hospital of USTC, University of Science and Technology of China, Hefei 230036, Anhui, China. ${ }^{3}$ Department of Laboratory, Division of Life Science and Medicine, the First Affiliated Hospital of USTC, University of Science and Technology of China, Hefei 230036, Anhui, China. ${ }^{4}$ Department of Pathology, Division of Life Science and Medicine, The First Affiliated Hospital of USTC, University of Science and Technology of China, Hefei 230036, Anhui, China.

Received: 15 June 2020 Accepted: 13 October 2021

Published online: 20 November 2021

\section{References}

1. Schneider DF, Chen H. New developments in the diagnosis and treatment of thyroid cancer. CA Cancer J Clin. 2013;63(6):374-94. https://doi.org/1 $0.3322 /$ caac.21195.

2. Lim H, Devesa SS, Sosa JA, Check D, Kitahara CM. Trends in thyroid cancer incidence and mortality in the United States, 1974-2013. Jama. 2017:317(13): 1338-48. https://doi.org/10.1001/jama.2017.2719. 
3. Adam MA, Pura J, Goffredo P, Dinan MA, Reed SD, Scheri RP, et al. Presence and number of lymph node metastases are associated with compromised survival for patients younger than age 45 years with papillary thyroid cancer. J Clin Oncol. 2015;33(21):2370-5. https://doi.org/10.1200/JCO.2014. 59.8391.

4. Yu XM, Wan Y, Sippel RS, Chen H. Should all papillary thyroid microcarcinomas be aggressively treated? An analysis of 18,445 cases. Ann Surg. 2011;254(4):653-60. https://doi.org/10.1097/SLA.0b013e318230036d.

5. Kim SM, Chun KW, Chang HJ, Kim BW, Lee YS, Chang HS, et al. Solitary lateral neck node metastasis in papillary thyroid carcinoma. World J Surg Oncol. 2014;12(1):109. https://doi.org/10.1186/1477-7819-12-109.

6. Yoo YH, Kim JA, Son EJ, Youk JH, Kwak JY, Kim EK, et al. Sonographic findings predictive of central lymph node metastasis in patients with papillary thyroid carcinoma: influence of associated chronic lymphocytic thyroiditis on the diagnostic performance of sonography. J Ultrasound Med. 2013;32(12):2145-51. https://doi.org/10.7863/ultra.32.12.2145.

7. Lee YS, Shin SC, Lim YS, Lee JC, Wang SG, Son SM, et al. Tumor locationdependent skip lateral cervical lymph node metastasis in papillary thyroid cancer. Head Neck. 2014:36(6):887-91. https://doi.org/10.1002/hed.23391.

8. Lan X, Sun W, Zhang H, Dong W, Wang Z, Zhang T. A meta-analysis of central lymph node metastasis for predicting lateral involvement in papillary thyroid carcinoma. Otolaryngol Head Neck Surg. 2015;153(5):731-8. https:// doi.org/10.1177/0194599815601412.

9. Chung YS, Kim JY, Bae JS, Song BJ, Kim JS, Jeon HM, et al. Lateral lymph node metastasis in papillary thyroid carcinoma: results of therapeutic lymph node dissection. Thyroid. 2009;19(3):241-6. https://doi.org/10.1089/thy.2008. 0244 .

10. NCCN. Clinical practice guidelines in oncology (NCCN guidelines). Thyroid carcinoma. Version 2.2020. National Comprehensive Cancer Network: Fort Washington; 2020

11. Zhou J, Yin L, Wei X, Zhang S, Song Y, Luo B, Li J, Qian L, Cui L, Chen W et al.: 2020 Chinese guidelines for ultrasound malignancy risk stratification of thyroid nodules: the C-TIRADS. Endocrine 2020;70(2):256-279, https://doi. org/10.1007/s12020-020-02441-y.

12. Li X, Zhang S, Zhang Q, Wei X, Pan Y, Zhao J, et al. Diagnosis of thyroid cancer using deep convolutional neural network models applied to sonographic images: a retrospective, multicohort, diagnostic study. Lancet Oncol. 2019;20(2):193-201. https://doi.org/10.1016/S1470-2 045(18)30762-9.

13. Hu Y-L, Cao X-Y, Zhou Y-R, Ye X-H, Wang J-X, Li X, et al. Management of Sonographically Suspicious Thyroid Nodules $1 \mathrm{~cm}$ or smaller and candidacy for active surveillance: experience of a tertiary Center in China. Endocr Pract. 2021;27(9):903-11. https://doi.org/10.1016/j.eprac.2021.02.006.

14. Kamaya A, Tahvildari AM, Patel BN, Willmann JK, Jeffrey RB, Desser TS. Sonographic detection of extracapsular extension in papillary thyroid cancer. J Ultrasound Med. 2015;34(12):2225-30. https://doi.org/10.7863/ ultra.15.02006

15. Wong KT, Ahuja AT. Ultrasound of thyroid cancer. Cancer Imaging. 2005 5(1):157-66. https://doi.org/10.1102/1470-7330.2005.0110.

16. Shin JH, Baek JH, Chung J, Ha EJ, Kim JH, Lee YH, et al. Ultrasonography diagnosis and imaging-based Management of Thyroid Nodules: revised Korean Society of Thyroid Radiology Consensus Statement and Recommendations. Korean J Radiol. 2016;17(3):370-95. https://doi.org/1 0.3348/kjr.2016.17.3.370.

17. Stack BC Jr, Ferris RL, Goldenberg D, Haymart M, Shaha A, Sheth S, et al. American Thyroid Association consensus review and statement regarding the anatomy, terminology, and rationale for lateral neck dissection in differentiated thyroid cancer. Thyroid. 2012;22(5):501-8. https://doi.org/10.1 089/thy.2011.0312

18. Sobin LH. Histological typing of thyroid tumours. Histopathology. 1990;16(5): 513. https://doi.org/10.1111/j.1365-2559.1990.tb01559.x

19. Kauffmann RM, Hamner JB, Ituarte PHG, Yim JH. Age greater than 60 years portends a worse prognosis in patients with papillary thyroid cancer: should there be three age categories for staging? BMC Cancer. 2018;18(1):316. https://doi.org/10.1186/s12885-018-4181-4

20. Qu N, Zhang L, Ji QH, Chen JY, Zhu YX, Cao YM, et al. Risk factors for central compartment lymph node metastasis in papillary thyroid microcarcinoma: a meta-analysis. World J Surg. 2015;39(10):2459-70. https://doi.org/10.1007/ s00268-015-3108-3.

21. Zhao Q, Ming J, Liu C, Shi $L, X u X$, Nie $X$, et al. Multifocality and total tumor diameter predict central neck lymph node metastases in papillary thyroid microcarcinoma. Ann Surg Oncol. 2013;20(3):746-52. https://doi.org/10.124 5/s10434-012-2654-2.

22. Liu MJ, Liu ZF, Hou YY, Men YM, Zhang YX, Gao LY, et al. Ultrasonographic characteristics of medullary thyroid carcinoma: a comparison with papillary thyroid carcinoma. Oncotarget. 2017;8(16):27520-8. https://doi.org/10.18632/ oncotarget.15897.

23. Moon HJ, Kwak JY, Kim EK, Kim MJ. A taller-than-wide shape in thyroid nodules in transverse and longitudinal ultrasonographic planes and the prediction of malignancy. Thyroid. 2011;21(11):1249-53. https://doi.org/10.1 089/thy.2010.0372.

24. Kaminski J, Miasaki FY, Paz-Filho G, Graf H, Carvalho GA. Treatment of hypothyroidism with levothyroxine plus liothyronine: a randomized, doubleblind, crossover study. Arch Endocrinol Metabolism. 2016;60(6):562-72. https://doi.org/10.1590/2359-3997000000192.

25. Kwak JY, Kim EK, Youk JH, Kim MJ, Son EJ, Choi SH, et al. Extrathyroid extension of well-differentiated papillary thyroid microcarcinoma on US. Thyroid. 2008;18(6):609-14. https://doi.org/10.1089/thy.2007.0345.

26. Lei J, Zhong J, Jiang K, Li Z, Gong R, Zhu J. Skip lateral lymph node metastasis leaping over the central neck compartment in papillary thyroid carcinoma. Oncotarget. 2017;8(16):27022-33. https://doi.org/10.18632/ oncotarget.15388.

27. Zhu F, Shen YB, Li FQ, Fang Y, Hu L, Wu YJ. The effects of Hashimoto thyroiditis on lymph node metastases in Unifocal and multifocal papillary thyroid carcinoma: a retrospective Chinese cohort study. Medicine. 2016; 95(6):e2674. https://doi.org/10.1097/MD.0000000000002674.

28. Wu Q, Li Y, Wang Y, Hu B. Sonographic features of primary tumor as independent predictive factors for lymph node metastasis in papillary thyroid carcinoma. Clin Transl Oncol. 2015;17(10):830-4. https://doi.org/10.1 007/s12094-015-1313-Z.

29. Ito $Y$, Fukushima M, Higashiyama T, Kihara M, Takamura Y, Kobayashi K, et al. Incidence and predictors of right paraesophageal lymph node metastasis of N0 papillary thyroid carcinoma located in the right lobe. Endocr J. 2013; 60(3):389-92. https://doi.org/10.1507/endocrj.EJ12-0362.

30. Azizi G, Faust K, Mayo ML, Farrell J, Malchoff C. Diagnosis of thyroid nodule with new ultrasound imaging modalities. VideoEndocrinol. 2019;7(1). https://doi.org/10.1089/ve.2020.0173.

31. Esfandiari $\mathrm{NH}$, Hughes DT, Yin $\mathrm{H}$, Banerjee $\mathrm{M}$, Haymart MR. The effect of extent of surgery and number of lymph node metastases on overall survival in patients with medullary thyroid cancer. J Clin Endocrinol Metab. 2014; 99(2):448-54. https://doi.org/10.1210/jc.2013-2942.

32. Lai $X$, Xia $Y$, Zhang B, Li J, Jiang Y. A meta-analysis of Hashimoto's thyroiditis and papillary thyroid carcinoma risk. Oncotarget. 2017;8(37):62414-24. https://doi.org/10.18632/oncotarget.18620.

\section{Publisher's Note}

Springer Nature remains neutral with regard to jurisdictional claims in published maps and institutional affiliations.

Ready to submit your research? Choose BMC and benefit from:

- fast, convenient online submission

- thorough peer review by experienced researchers in your field

- rapid publication on acceptance

- support for research data, including large and complex data types

- gold Open Access which fosters wider collaboration and increased citations

- maximum visibility for your research: over $100 \mathrm{M}$ website views per year

At $\mathrm{BMC}$, research is always in progress.

Learn more biomedcentral.com/submission 